\title{
Advancement in Indoor Vertical Farming for Microgreen Production
}

\author{
Preethi Rajan, Rajasekaran R. Lada, Mason T. MacDonald \\ Department of Plant, Food, and Environmental Sciences, Faculty of Agriculture, Dalhousie University Truro, Truro, N.S., Canada \\ Email: *mason.ma cdonald@dal.ca
}

How to cite this paper: Rajan, P., Lada, R.R. and MacDonald, M.T. (2019) Advancement in Indoor Vertical Farming for Microgreen Production. American Journal of Plant Sciences, 10, 1397-1408. https://doi.org/10.4236/ajps.2019.108100

Received: July 4, 2019

Accepted: August 24, 2019

Published: August 27, 2019

Copyright $\odot 2019$ by author(s) and Scientific Research Publishing Inc. This work is licensed under the Creative Commons Attribution International License (CC BY 4.0).

http://creativecommons.org/licenses/by/4.0/ (c) (i) Open Access

\begin{abstract}
With the growing global urban population and the emergence of megacities, there is a huge demand for arable land to meet the food demand and reduce malnutrition. Conventional agricultural practices lead to deforestation of the land for crop production and agricultural intensification to produce higher yield per unit area. These activities have been established to have negative impact on the environment thereby causing soil and water pollution. It is important to consider the use of vertical farming technology, which utilizes both horizontal and vertical space, and efficiently uses nutrients, water, and time (off season production with artificial lighting) more effectively to produce higher yield per unit volume of space than the conventional outdoor farming. Microgreens are taken into consideration to be grown under innovative vertical farming technology since they are rich in phytonutrients and they can be harvested in a short period of time. This paper reviews the current growing conditions of microgreens in vertical farming such as crop selection, media, light, nutrient solution, and containers while identifying knowledge gaps. Further, study in this area may lead to improved growing conditions to help solve the global issues and challenges surrounding food security, safety, and resource optimization.
\end{abstract}

\section{Keywords}

Vertical Farming, Microgreens, Phytonutrients, BioStrate,

Light Emitting Diodes, Plant Nutrition

\section{Introduction}

Megacities are emerging as a result of rural to urban transition due to increased income level and urban population [1]. Because of the projected growing urban 
population, there is a huge requirement for arable land to feed the population. The conversion of forestland into arable land contributes to deforestation, contributing to the depletion of natural resources like ground water, reduction of biodiversity due to loss of habitat, and increased soil erosion and greenhouse gas emission. At the same time, the urban population started preferring more processed foods as opposed to traditional foods, resulting in an increased level of health issues [2]. This new pattern of consumption of more processed foods like meat, fruits, and vegetables requires changes in agricultural production systems, especially agricultural intensification. However, agricultural intensification at the field level would result in the intense application of fertilizers and plant protection chemicals, which would further increase pollution of soil and ground water.

Development of sustainable agriculture is important to produce stable and healthy food considering food safety and security by managing the resources in a more efficient manner without causing any adverse effect to the environment [3]. Urban cities are lacking strategies, processes and technologies to provide stable, healthy, and safe food for growing populations. Understanding successful innovations by the megacities can help manage the future of our planet [1]. Intensive organic farming is another tool in sustainable agriculture but requires the application of bulk quantity of organic inputs for nutrition and pest control, which adds to the cost of production and possible environmental pollution. In such a case, the vertical farming in megacities plays a crucial role in providing food and nutritional security with resource efficiency.

The cultivation of such high value crops under different innovation techniques results in increased cost of production because of the necessity for controlled environmental conditions, continuous supply and recirculation of good quality irrigation water and nutrients, and post-harvest handling costs until the product reaches the consumer. This would automatically increase the market price of the produce, which cannot be afforded by people with low-income. Thus, it is essential to design innovative vertical farming technologies, which lower production costs without sacrificing product quality. Microgreens are utilized as a suitable crop since they are rich in phytonutrients and vitamins [4] while not necessarily needing external application of fertilizers. Microgreens are tender immature greens of vegetables, herbs, and grains [5] providing intense flavors, vivid colors, and tender textures. Microgreens currently fetch a high price in the market because of its rich nutrition content and post harvest practices, such that the people with low income level cannot afford to buy them for enhancing their nutrition by adding them in their regular diet. This review is concerned about the production of highly nutritious and safe food (without microbial contamination) with minimal post-harvest wastage by reducing the cost of production using containerized vertical farming technology.

\section{Vertical Farming Technology}

Vertical farming facilitates the production of high value crops with higher yield than obtained from conventional farming by efficient utilization of resources 
such as water, nutrients, space and time, thereby, reducing carbon footprint [6]. Vertical farming technology does not require huge arable land to produce crops and thus is agriculturally independent. This innovation utilizes both the horizontal and vertical spaces more effectively, thereby, producing higher yield per unit volume under controlled environmental conditions of temperature, light, carbon dioxide and humidity. There are different types of vertical farming innovations like hydroponics, aeroponics, and aquaponics where the nutrients are effectively utilized and monitored for physical and chemical parameters like quality, $\mathrm{pH}$, and solubility in water. Since vertical farming is experimented within a closed and controlled environment, sunlight as a source of light for carrying out photosynthesis is replaced by artificial lights with different spectra and intensities. In such a case, LED lights are more effective with high energy use efficiency and durability than traditional light sources like fluorescent lamps [6].

\subsection{Hydroponics}

Commercial hydroponics is a modern technology involving plant growth in nutrient solution without the use of soil as a rooting medium. This system involves the application of inorganic nutrients through irrigation water and recirculation of nutrient solution thereby avoiding wastage by leaching [7]. The main advantages of this system include mitigation of problems related to soil such as soil-borne diseases, poor physical and chemical properties with decreased application of plant protection chemicals. Hydroponics results in enhancement of quality of fruits and flowers with precise application of nutrients. The disadvantages of hydroponics are higher installation cost for the soilless culture system, investment cost and technical skills needed to manage with them to obtain maximum yield and product quality within controlled environmental growing conditions [7].

\subsection{Aeroponics}

Aeroponics represents the production of crops under air or mist environment without the use of soil as the rooting medium. In this system, the roots of the plants are exposed to the environment and can grow freely. The advantage of this system is that, it uses only $10 \%$ of the water needed for hydroponics and aquaponics because of the use of mist and hence the roots can access much more oxygen than in hydroponics and aquaponics. The disadvantages of this system are that a failure in the system would stop the flow of nutrient solution in the form of mist and may lead to the death of the crop [7].

\subsection{Aquaponics}

Aquaponics is a system which combines both hydroponics to produce crops and aquaculture to cultivate fish. The advantage of this system is that the fecal matter of fish would naturally become the organic fertiliser for the crops. This would eliminate the necessity for the solid waste disposal which would impose high 
management cost. The disadvantages of this system include high investment cost and complications within the system, such as power failure or pipeline blockage that can lead to complete loss of crop and fish [8].

Hence, the containerized soilless culture of crops requires attention for reducing the cost of production with minimal post-harvest handling, enhanced food safety and ready to market and consume strategy.

\section{Vertical Farming Considerations}

\subsection{Crop Selection}

Crop selection would be an important factor to be considered which is highly influenced by suitability, consumer preference, demand, and market. High value commercial crops are suitable for vertical farming, which secures high demand, increased preference by the consumers, and market price to offset the increased cost of production. The crops with less maintenance, such as reduced water consumption with high water use efficiency and reduced nutrient application, would alleviate cost of production. Over the past twenty years, there is huge demand for vegetables which possess high health benefits [9]. Microgreens, known as "vegetable confetti and specialty crop" [10], secured its importance in modern food pattern and consumer preference. Microgreens are tender immature greens of vegetables, herbs and grains [5] providing intense flavors, vivid colors and tender textures. Therefore, they can be added in salad, soups, and sandwiches to enhance color, texture and flavor [10]. It was reported that microgreens contain higher amounts of phytonutrients (ascorbic acid, $\beta$-carotene, $\alpha$-tocopherol and phylloquinone) and minerals ( $\mathrm{Ca}, \mathrm{Mg}, \mathrm{Fe}, \mathrm{Mn}, \mathrm{Zn}, \mathrm{Se}$ and $\mathrm{Mo}$ ) and lower nitrate content than their mature leaf counterparts thereby acting as a good source of minerals for satisfying adult and child diet requirements without exposing them to harmful nitrates [4]. It is very important to select the crop which contains high phytonutrients, carotenoids, antioxidants and medicinal properties besides economical and commercial value. The commercially grown microgreens rich in vitamins such as $\beta$-Carotene, Violaxanthin, and Lutein/Zeaxanthin and phytonutrients are listed in Table 1.

\subsection{Media Selection}

A growth medium is a material that supports the growth of the plant. Various non-toxic porous materials are used as plant growth substrates, including rockwool, perlite, pumice, expanded clay, various volcanic materials, polyurethane foam and coconut coir dust (coir fibre obtained from coconut husk) [7]. A balanced distribution of small and larger pores is required in a substrate to ensure adequate availability of water to the plants without affecting the supply of oxygen to the roots [7]. Microgreens can be grown in a standard, sterile, loose, soilless germinating media like peat, vermiculite, perlite and coconut fibre. An alternative production system includes fiber like mat or lining (acting as seeding bed) being placed over the bottom of a burlap or a food-grade plastic tray which 
Table 1. Benefits of several commercially grown microgreens rich in phytonutrients and vitamins [5].

\begin{tabular}{ccc}
\hline S.NO & Species & Benefits \\
\hline 1 & Brassica oleracea L. varcapitata & Rich in ascorbic acid, vitamins, tocopherols \\
2 & Amaranthus hypochondriacus L. & Rich in phylloquinone, vitamins \\
3 & Coriandrum sativum & Rich in phylloquinone, vitamins, tocopherols \\
4 & Raphanus sativus & Rich in phylloquinone, ascorbic acid \\
\hline
\end{tabular}

is specifically designed for microgreens by the company "Sure to Grow" (Beachwood, $\mathrm{OH}$ ). These mat systems are often used in nutrient film technique [10].

In soilless culture, peat is commercially used a medium for growing microgreens but in Thailand, peat is imported from Europe and thus, becomes an expensive medium. Therefore, an experiment was conducted to determine the potential of other biomaterials as a substitute for peat, resulting in more affordable growth media. The results showed that the locally available biomaterial like coconut coir dust, sugarcane filter cake, or vermicompost as a media were found to be effective and affordable to produce microgreens with maximum yield while maintaining safe levels of Escherichia coli, Staphylococcus aureus, and Salmonella $s p$ [11]. In another experiment, Rapini microgreens were grown under cost-effective, ecofriendly, and biodegradable recycled textile fiber and jute kenaf fiber in comparison with expensive and non-renewable peat and synthetic mats (Sure to Grow product, Beachwood, OH, US). It was found that the plants grown under textile fibre and jute showed higher yield with lower nitrate content than peat and synthetic mats and, thus, proved to be a good alternative to peat and synthetic mats [12].

BioStrate is the newly emerging media for microgreen cultivation and is readily available in the market. But there are no literature evidence related to the usage of BioStrate as a medium for microgreen cultivation. BioStrate is a bio-based textile especially for growing hydroponic microgreens and baby salad greens. It is a blend of biopolymers and natural fibers designed to efficiently manage applied water for optimal growth (Grow-Tech LLC product and the source is from green growers). BioStrate is light weight and easy to use. It is compostable. So, BioStrate is to be considered as a medium to produce microgreens and its potential of producing higher yield in comparison with other biodegradable ecofriendly media is to be determined.

There are no literatures on the growth of microgreens under liquid gel media or semisolid media containing all such essential nutrients for microgreen growth and development which eliminates the further application of water and nutrient solution for microgreens growth. Murashige-Skoog medium which is commonly utilised in plant tissue culture can be considered for microgreen production.

\subsection{Light}

\subsubsection{Light Source}

Light is an important factor, which is required by the plants to carry out photo- 
synthesis. Plants grown in the field derive their source of light from theSun. Since plants are grown within controlled environmental conditions under vertical farming technology, they require external sources of light to carry out photosynthesis. The traditional light sources such as high-pressure sodium lamps and metal halide lamps generate significant heat and are not energy efficient or cost-effective with respect to plant growth. Thus, solid-state light-emitting diode (LED) lights have been introduced to solve these problems and enhance the quality of the produce. LED lights possess high energy efficiency, low maintenance cost and longevity [13] three parameters of light such as intensity, quality and duration should be considered which have different effects on the growth of the crop and the quality of the produce [14]. Plants require $400-700 \mathrm{~nm}$ wavelengths of light for photosynthesis, which is considered as visible light spectrum and photosynthetically active radiation. The blue, green and red-light spectra are absorbed by the plant pigments and have strong influence on the vegetative growth and development of the plants. The far red and infra red light have an influence on the germination and flowering but is less absorbed by the leaves [13]. However, each plant species may require a specific spectrum of light, intensity and duration and there is significant knowledge gap for microgreen production on the suitability of light spectra, intensity and duration.

\subsubsection{LED Spectrum}

When an experiment was conducted to determine the effects of LEDs on net photosynthetic rate, growth, and leaf stomata of chrysanthemum plantlets in vitro grown in MS medium, it was found that the net photosynthetic rate was highest under red $(650 \mathrm{~nm})$ and blue $(440 \mathrm{~nm})$ combination and lowest under blue-far red $(720 \mathrm{~nm})$ combination and blue. Red and red-far red combination resulted in the highest stem elongation but with stem fragility. Shoot growth excluding stem elongation was the greatest under red-blue combination and fluorescent light [15]. When Lactucasativa of variety red curly lettuce was grown under different light spectrum, it was found that anthocyanin synthesis, protein content and phenylalanine ammonia-lyase enzyme activity were highest in combined radiation of blue and red-light treatment [16]. In another study, where red and green basil (Ocimum basilicum) microgreens were grown with blue and red LED, it was found that growth of microgreens was enhanced with predominantly blue illumination showing larger cotyledon area and higher fresh mass, enhanced chlorophyll a, and anthocyanin pigments contents. Stimulation of phenolic synthesis and free radical scavenging activity were improved by predominantly red light in the green cultivar and blue light in the red cultivar [17], which indicates that LED light has an influence on the colour of the leaf.

\subsubsection{LED and Photosynthetic Photon Flux Density}

In an experiment conducted to determine the influence of green, red, and blue LED at low and high light intensities on photosynthetic activity of lettuce leaves, it was found that biomass and photosynthetic parameters increased at a light in- 
tensity of $238 \mu \mathrm{mol} \cdot \mathrm{m}^{-2} \cdot \mathrm{s}^{-1}$ versus $80 \mu \mathrm{mol} \cdot \mathrm{m}^{-2} \cdot \mathrm{s}^{-1}$ under blue LED illumination. High intensity blue LEDs enhanced plant growth by controlling the expression of chloroplast proteins which optimize the photosynthetic performance [18]. When the Brassicaceae microgreens are exposed to LED lights of varied levels of illumination spectra and intensity, the highest carotenoid content was recorded at $330-440 \mu \mathrm{mol} \cdot \mathrm{m}^{-2} \cdot \mathrm{s}^{-1}$ in red pakchoi and tatsoi and $110-220 \mu \mathrm{mol} \cdot \mathrm{m}^{-2} \cdot \mathrm{s}^{-1}$ in mustard [19]. In another study, which was done on the suitability of light irradiance level for optimal growth and nutrient content in borage microgreens, it was found that the lowest nitrate contents and highest antioxidant contents were recorded at moderate, $330-440 \mu \mathrm{mol} \cdot \mathrm{m}^{-2} \cdot \mathrm{s}^{-1}$ irradiance levels and hence suitable for the cultivation of borage microgreens [20].

\subsubsection{LEDs and Energy Efficiency}

Lettuce crops grown with red and blue LED lighting (95\% red and 5\% blue) used $50 \%$ less energy per unit dry biomass accumulated than under traditional light sources, which indicates that the significant reduction in energy consumption for plant-growth by using LED than traditional light sources [21]. In an experiment on the indoor cultivation of basil and strawberry, it was found that the plants expressed increased biomass, fruit yield, antioxidant content and reduced nitrate content when treated with LED with highest energy use efficiency than traditional fluorescent lamps and spectral red: blue ratio of 0.7 was essential for proper plant growth with improved nutraceutical properties [22].

From the literature review, it is found that when the microgreens are treated with red and blue LED combination, they showed highest photosynthetic activity but the exact ratio of blue and red-light combination at which the results are obtained are not evident. Thus, it is essential to consider the production of microgreens at different ratios of red and blue combination under different light intensities.

\subsection{Carbon Dioxide, Temperature and Humidity}

The environmental factors such as carbon dioxide, temperature and humidity play a crucial role in the growth and development of plants throughout their life cycles. Their levels are specific and critical for different stages of plant growth. In an experiment conducted to determine the impact of free air carbon dioxide enrichment on development and progress in cotton (Gossypium hirsutum), the results were found that carbon dioxide enrichment resulted in significant increase in photosynthesis and biomass of leaves, stems and roots, reduced evapotranspiration, changes in root morphology and increased soil respiration [23].

When experiments have been conducted to determine the effects of atmospheric humidity on sugar beet, wheat and kale, the results were found that the plants showed increases in growth with increased atmospheric humidity. The leaf area of sugar beet and kale plants was also increased with increased humidity due to the increase in number of cells [24]. 
Each plant species will require optimum temperature to show maximum rate of plant growth and development. Both the atmospheric temperature and the soil temperature will influence different stages of plant development such as vegetative and reproductive stage. For instance, the vegetative growth of the plant requires comparatively higher optimum temperature than reproductive stage [25].

There are many literatures pertaining to the effect of climatic factors such as carbon dioxide, temperature and humidity on plant growth and development both indoor (green house) and outdoor (field) conditions but there are no such studies on microgreens. From the previous related works, it is important to consider their impact of climatic factors and their regulation to produce maximum growth and yield of microgreens which are grown indoor.

\subsection{Nutrients}

Plants require both macro- and micro-nutrients for their growth and development. Vertical farming technology involves the soilless culturing of plants with application of nutrient solution, especially, inorganic fertilizer to the plants through soilless medium. The Hoagland solution developed by Hoagland and Arnon (1938) with definite composition is a hydroponic nutrient solution, which provides every essential nutrients for plant growth [26]. The composition of Hoagland solution is given in Table 2 [26].

The commercial crops grown under soilless culture yield good quality produce when supplemented with the nutrient solution of specific composition based on the crop, the growth stage, the climatic conditions, the substrate, or hydroponic system used. Thus, the standard formula is not always applicable to all the crops [7]. When experimenting the plants with continuous flow of nutrient solution, it was found that there is a certain minimum concentration below which uptake is no longer possible at the required rate. At the other extreme of concentration, luxury consumption may lead to internal toxicity [27]. Thus, it is not necessary to apply nutrients unless required by the crop for its growth. Seeds contain a certain amount of nutrients for germination and initial growth. Though the seeds do not require nutrient application for germination initially, they require nutrients for proper growth and development. Thus, it is essential to grow plants under different concentration of nutrient solution with a control to determine the optimum concentration for maximum growth which can be derived through growth curve.

In an experiment conducted on Brassica microgreens to study the impact of light intensity and quality of sole source LED on their growth, morphology and nutrient content, 25\% Hoagland's no. 1 nutrient solution was applied to the microgreens after 5 days of sowing to provide essential nutrients such as nitrogen, phosphorus, potassium, calcium, magnesium, iron, manganese, zinc, copper, boron and molybdenum [28]. There are many different liquid fertilisers commercially available in the market for microgreens. In an experiment conducted to compare the nutrient content on cabbage and lettuce microgreens grown on 
Table 2. Hoagland solution composition.

\begin{tabular}{|c|c|c|c|c|}
\hline S.No & Chemicals & Formula & Mol.wt (gram) & $\begin{array}{c}\text { Per L nutrient } \\
\text { solution }\end{array}$ \\
\hline 1 & Potassium nitrate & $\mathrm{KNO}_{3}$ & 101.1 & $5 \mathrm{ml}$ of $1 \mathrm{M}$ \\
\hline 2 & Calcium nitrate & $\mathrm{Ca}\left(\mathrm{NO}_{3}\right)_{2} \cdot 4 \mathrm{H}_{2} \mathrm{O}$ & 236.15 & $5 \mathrm{ml}$ of $1 \mathrm{M}$ \\
\hline 3 & Monopotassium phosphate & $\mathrm{KH}_{2} \mathrm{PO}_{4}$ & 136.09 & $1 \mathrm{ml}$ of $1 \mathrm{M}$ \\
\hline \multirow[t]{3}{*}{4} & Magnesium sulfate & $\mathrm{MgSO}_{4} \cdot 7 \mathrm{H}_{2} \mathrm{O}$ & 246.47 & $2 \mathrm{ml}$ of $1 \mathrm{M}$ \\
\hline & Micronutrient stock solution & & & $1 \mathrm{ml}$ of stock solution \\
\hline & Boric acid & $\mathrm{H}_{3} \mathrm{BO}_{3}$ & 61.83 & $2.86 \mathrm{~g}$ \\
\hline \multirow{4}{*}{5} & Manganese chloride 4 hydrate & $\mathrm{MnCl}_{2} \cdot 4 \mathrm{H}_{2} \mathrm{O}$ & 197.9 & $1.81 \mathrm{~g}$ \\
\hline & Zinc sulfate - 7 hydrate & $\mathrm{ZnSO}_{4} \cdot 7 \mathrm{H}_{2} \mathrm{O}$ & 287.54 & $0.22 \mathrm{~g}$ \\
\hline & Copper sulfate - 5 hydrate & $\mathrm{CuSO}_{4} \cdot 5 \mathrm{H}_{2} \mathrm{O}$ & 249.7 & $0.08 \mathrm{~g}$ \\
\hline & 85\% Molybdic acid & $\mathrm{MoO}_{3} \cdot \mathrm{H}_{2} \mathrm{O}$ & 161.95 & $0.02 \mathrm{~g}$ \\
\hline 6 & Iron chelate & Fe-EDTA & & $1-5 \mathrm{ml}$ of $1000 \mathrm{mg} / \mathrm{l}$ \\
\hline
\end{tabular}

vermicompost and hydroponic growing pads, [29] used 0.4\% solution of General Hydroponics "FloraGro" Advanced Nutrient System 2-1-6 ("FloraGro"; GH Inc., Sebastopol, CA, USA) on the $7^{\text {th }}$ day of growth of microgreens. However, there are not many experiments conducted on the application of commercial liquid fertilisers on microgreens. Thus, the application of commercial liquid fertiliser containing all such essential nutrients for enhanced growth of microgreens shall be considered for microgreens.

\subsection{Container Selection}

The container plays a major role in the growth of plants by providing support to the plants and regulating the environmental conditions such as temperature, gaseous exchange and relative humidity. In an experiment conducted to determine the effect of LED on carotenoid content in Brassicaceae microgreens, the crops were grown in peat substrate in 0.5 litre plastic vessels [19]. In another experiment on post harvest physiology of microgreens such as red cabbage and arugula, the crops were sown in slotted $28 \mathrm{~cm} \times 54.5 \mathrm{~cm}$ trays filled with organic soilless potting mix (Sun Gro Sunshine Organic Sphagnum Blend, SunGro Horticulture Canada Ltd.). Immediately after sowing, the trays were watered and covered with another slotted tray for 2 days to maintain the relative humidity [30]. In an experiment conducted to determine the improvement in growth and bioactive compounds in basil microgreens through blue and red LED illumination, [17] used clear plastic boxes of dimension $14 \times 14 \times 8 \mathrm{~cm}$ containing soil and peat moss in 2:1 ratio as a medium for sowing 150 seeds. When the experiment was conducted on cabbage and lettuce microgreens to determine their nutrient content in vermicompost and hydroponic growing pads, [29] used 5 inch $\times 5$ inch insert trays containing vermicompost and Micro-Mat hydroponic pads separately for sowing microgreens seeds. 
From the literatures, it is found that the microgreens are commonly grown in plastic trays or vessels and the trays are not covered with lids. This implies that the microgreens are grown exposed to the climatic conditions until the harvest period and once they are harvested, the microgreens require separate packaging material for marketing which would increase the cost of production. Containerised vertical farming technology can be suggested to grown microgreens in a closed container which provides suitable microclimate by considering the capacity of the container, head space for gaseous exchange, availability, cost, light penetrance and ease in handling (light weight) and marketing. There might be risks of microbial contamination due to the development of high humidity within the closed containers which can be overcome by sterilising the containers under ultraviolet light for 15 minutes. There might also be a problem of gaseous exchange in closed containers which can be overcome by making tiny holes in the lid.

\section{Conclusion}

In the past few decades, microgreens are emerging as a new speciality crop by possessing high demand and market value among the consumers. Microgreens are commercially grown in vertical racks under artificial lighting systems. They are assumed to solve the global issues of food and nutritional safety and security since they possess high nutritional value. From the literature reviews on various growing conditions of microgreens such as medium, light, nutrient solution and containers, it is found that the current method of growing microgreens possesses few drawbacks and knowledge gaps which can be rectified by modifying their growing conditions. The innovative growing conditions such as BioStrate (made of fibre) and Murashige-Skoog (plant tissue culture) media and Containerised vertical farming technology involving the production of microgreens in closed containers should be taken into consideration. The appropriate and inexpensive production system of microgreens will facilitate their application in places of commercial microgreen production on a large scale, war crisis, famine and extreme climatic conditions.

\section{Conflicts of Interest}

The authors declare no conflicts of interest regarding the publication of this paper.

\section{References}

[1] Jowell, A., Zhou, B. and Barry, M. (2017) The Impact of Megacities on Health: Preparing for a Resilient Future. The Lancet Planetary Health, 1, e176-e178. https://doi.org/10.1016/S2542-5196(17)30080-3

[2] Food and Agriculture Organization of the United Nations (2017) The Future of Food and Agriculture: Trends and Challenges. Food and Agriculture Organization of the United Nations, Rome.

[3] Lada, R.R., Maijers, W. and Nieboer, S. (2018) Innovative Indoor Horticultural Sys- 
tems (IHORT) for the 21st Century. Current Investigation in Agriculture and Current Research, 4, 576-581. https://doi.org/10.32474/CIACR.2018.04.000194

[4] Pinto, E., Almeida, A.A., Aguiar, A.A. and Ferreira, I.M.P.L.V.O. (2015) Comparison between the Mineral Profile and Nitrate Content of Microgreens and Mature Lettuces. Journal of Food Composition and Analysis, 37, 38-43. https://doi.org/10.1016/j.jfca.2014.06.018

[5] Xiao, Z., Lester, G.E., Luo, Y. and Wang, Q. (2012) Assessment of Vitamin and Carotenoid Concentrations of Emerging Food Products: Edible Microgreens. Journal of Agricultural and Food Chemistry, 60, 7644-7651. https://doi.org/10.1021/jf300459b

[6] Specht, K., Siebert, R., Hartmann, I., Freisinger, U.B., Sawicka, M., Werner, A., Thomaier, S., Henckel, D., Walk, H. and Dierich, A. (2014) Urban Agriculture of the Future: An Overview of Sustainability Aspects of Food Production in and on Buildings. Agriculture and Human Values, 31, 33-51. https://doi.org/10.1007/s10460-013-9448-4

[7] Savvas, D. (2003) Hydroponics: A Modern Technology Supporting the Application of Integrated Crop Management in Greenhouse. Journal of Food, Agriculture and Environment, 1, 80-86.

[8] Partridge, S.K. (2003) Automated PH Monitoring System for Integration into Environmental Controllers. 58. https://digitalcommons.wpi.edu/mqp-all/2892

[9] Drewnowski, A. and Gomez-Carneros, C. (2000) Bitter Taste, Phytonutrients, and the Consumer: A Review. The American Journal of Clinical Nutrition, 72, 1424-1435. https://doi.org/10.1093/ajcn/72.6.1424

[10] Treadwell, D.D., Hochmuth, R., Landrum, L. and Laughlin, W. (2010) Microgreens: A New Specialty Crop. University of Florida IFAS Extension HS1164.3.

[11] Muchjajib, U., Muchjajib, S., Suknikom, S. and Butsai, J. (2015) Evaluation of Organic Media Alternatives for the Production of Microgreens in Thailand. Acta Horticulturae, 1102, 157-162. https://doi.org/10.17660/ActaHortic.2015.1102.19

[12] Di Gioia, F., De Bellis, P., Mininni, C., Santamaria, P. and Serio, F. (2017) Physicochemical, Agronomical and Microbiological Evaluation of Alternative Growing Media for the Production of Rapini (Brassica Rapa L.) Microgreens: Recycled Fibrous Materials for Rapini Microgreens Production. Journal of the Science of Food and Agriculture, 97, 1212-1219. https://doi.org/10.1002/jsfa.7852

[13] Singh, D., Basu, C., Meinhardt-Wollweber, M. and Roth, B. (2015) LEDs for Energy Efficient Greenhouse Lighting. Renewable and Sustainable Energy Reviews, 49, 139-147. https://doi.org/10.1016/j.rser.2015.04.117

[14] Nishio, J.N. (2000) Why Are Higher Plants Green? Evolution of the Higher Plant Photosynthetic Pigment Complement. Plant, Cell and Environment, 23, 539-548. https://doi.org/10.1046/j.1365-3040.2000.00563.x

[15] Kim, S.-J., Hahn, E.-J., Heo, J.-W. and Paek, K.-Y. (2004) Effects of LEDs on Net Photosynthetic Rate, Growth and Leaf Stomata of Chrysanthemum Plantlets in Vitro. Scientia Horticulturae, 101, 143-151. https://doi.org/10.1016/j.scienta.2003.10.003

[16] Heo, J.-W., Kang, D.-H., Bang, H.-S., Hong, S.-G., Chun, C.-H. and Kang, K.-K. (2012) Early Growth, Pigmentation, Protein Content, and Phenylalanine Ammonia-Lyase Activity of Red Curled Lettuces Grown under Different Lighting Conditions. Korean Journal of Horticultural Science and Technology, 30, 6-12. https://doi.org/10.7235/hort.2012.11118

[17] Lobiuc, A., Vasilache, V., Oroian, M., Stoleru, T., Burducea, M., Pintilie, O. and 
Zamfirache, M.-M. (2017) Blue and Red LED Illumination Improves Growth and Bioactive Compounds Contents in Acyanic and Cyanic Ocimum basilicum L. Microgreens. Molecules, 22, 2111. https://doi.org/10.3390/molecules22122111

[18] Muneer, S., Kim, E., Park, J. and Lee, J. (2014) Influence of Green, Red and Blue Light Emitting Diodes on Multiprotein Complex Proteins and Photosynthetic Activity under Different Light Intensities in Lettuce Leaves (Lactuca sativa L.). International Journal of Molecular Sciences, 15, 4657-4670. https://doi.org/10.3390/ijms15034657

[19] Brazaitytè, A., Sakalauskienė, S., Samuolienė, G., Jankauskienė, J., Viršilè, A., Novičkovas, A., Sirtautas, R., Miliauskienė, J., Vaštakaitė, V., Dabašinskas, L. and Duchovskis, P. (2015) The Effects of LED Illumination Spectra and Intensity on Carotenoid Content in Brassicaceae Microgreens. Food Chemistry, 173, 600-606. https://doi.org/10.1016/j.foodchem.2014.10.077

[20] Viršile, A. and Sirtautas, R. (2013) Light Irradiance Level for Optimal Growth and Nutrient Contents in Borage Microgreens. Proceedings of the International Scientific Conference: Rural Development, Vol. 6, 272.

[21] Poulet, L., Massa, G.D., Morrow, R.C., Bourget, C.M., Wheeler, R.M. and Mitchell, C.A. (2014) Significant Reduction in Energy for Plant-Growth Lighting in Space Using Targeted LED Lighting and Spectral Manipulation. Life Sciences in Space Research, 2, 43-53. https://doi.org/10.1016/j.lssr.2014.06.002

[22] Piovene, C., Orsini, F., Bosi, S., Sanoubar, R., Bregola, V., Dinelli, G. and Gianquinto, G. (2015) Optimal Red: Blue Ratio in Led Lighting for Nutraceutical Indoor Horticulture. Scientia Horticulturae, 193, 202-208. https://doi.org/10.1016/j.scienta.2015.07.015

[23] Hendrey, G.R., Lewin, K.F. and Nagy, J. (1993) Free Air Carbon Dioxide Enrichment: Development, Progress, Results. In: Rozema, J., Lambers, H., Van de Geijn, S.C. and Cambridge, M.L., Eds., $\mathrm{CO}_{2}$ and Biosphere, Springer, Berlin, 17-32. https://doi.org/10.1007/978-94-011-1797-5_2

[24] Ford, M.A. and Thorne, G.N. (1974) Effects of Atmospheric Humidity on Plant Growth. Annals of Botany, 38, 441-452. https://doi.org/10.1093/oxfordjournals.aob.a084827

[25] Hatfield, J.L. and Prueger, J.H. (2015) Temperature Extremes: Effect on Plant Growth and Development. Weather and Climate Extremes, 10, 4-10. https://doi.org/10.1016/j.wace.2015.08.001

[26] Hoagland, D.R. and Dennis, R. (1938) The Water-Culture Method for Growing Plants without Soil.

[27] Steiner, A.A. (1961) A Universal Method for Preparing Nutrient Solutions of a Certain Desired Composition. Plant and Soil, 15, 134-154.

https://doi.org/10.1007/BF01347224

[28] Gerovac, J.R., Craver, J.K., Boldt, J.K. and Lopez, R.G. (2016) Light Intensity and Quality from Sole-Source Light-Emitting Diodes Impact Growth, Morphology, and Nutrient Content of Brassica Microgreens. HortScience, 51, 497-503. https://doi.org/10.21273/HORTSCI.51.5.497

[29] Weber, C.F. (2016) Nutrient Content of Cabbage and Lettuce Microgreens Grown on Vermicompost and Hydroponic Growing Pads. Journal of Horticulture, 3, 1-5. https://doi.org/10.4172/2376-0354.1000190

[30] Berba, K.J. and Uchanski, M.E. (2012) Post-Harvest Physiology of Microgreens. Journal of Young Investigators, 24, 5. 